\title{
A technique for safe ulcer floor closure using an over-the-scope clip after endoscopic submucosal dissection of lesions adjacent to the ampulla of Vater
}

In duodenal endoscopic submucosal dissection (ESD), complete defect closure is required because exposure of the postESD ulcer floor to pancreatic juice and bile can lead to delayed perforation and bleeding [1-3]. Closure with an overthe-scope (OTS) clip has been reported as being convenient and useful in the prevention of postoperative adverse events [1,2]. However, if lesions are adjacent to the ampulla of Vater, there is a risk of severe pancreatitis developing because the ampulla of Vater may get sucked into the hood and be closed with an OTS clip during ulcer floor closure [4]. It is impossible to ensure exclusion of the ampulla of Vater during ulcer floor closure, because the ulcer floor needs to be sucked with full force into the hood, along with the surrounding normal mucosa, which inevitably results in a blind operation when the OTS clip is released. Therefore, previously, we have had to abandon closure with an OTS clip, having no choice but to perform endoscopic drainage [5]. Herein, we introduce a technique for safe closure of a post-ESD ulcer floor adjacent to the ampulla of Vater with an OTS clip.

The entire procedure is shown in $\mathbf{V i}$ deo 1. First, an anchor clip is placed on the ampulla side of the ulcer floor, with this clip playing a very important role in preventing accidental closure of the ampulla of Vater ( $\mathbf{F i g . 1} \mathbf{1} \mathbf{a , b}$ ). The OTS clip is then attached and the endoscope is reinserted up to the ulcer floor. Subsequently, after it has been confirmed that the anchor clip is outside the hood, the entire ulcer floor is fully aspirated and

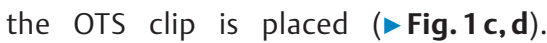
Thereby, the risk of the ampulla of Vater getting sucked into the hood is definitely avoided.

With the use of an endoclip as an anchor, even post-ESD ulcer floors that are adjacent to the ampulla of Vater can be safely closed with an OTS clip.
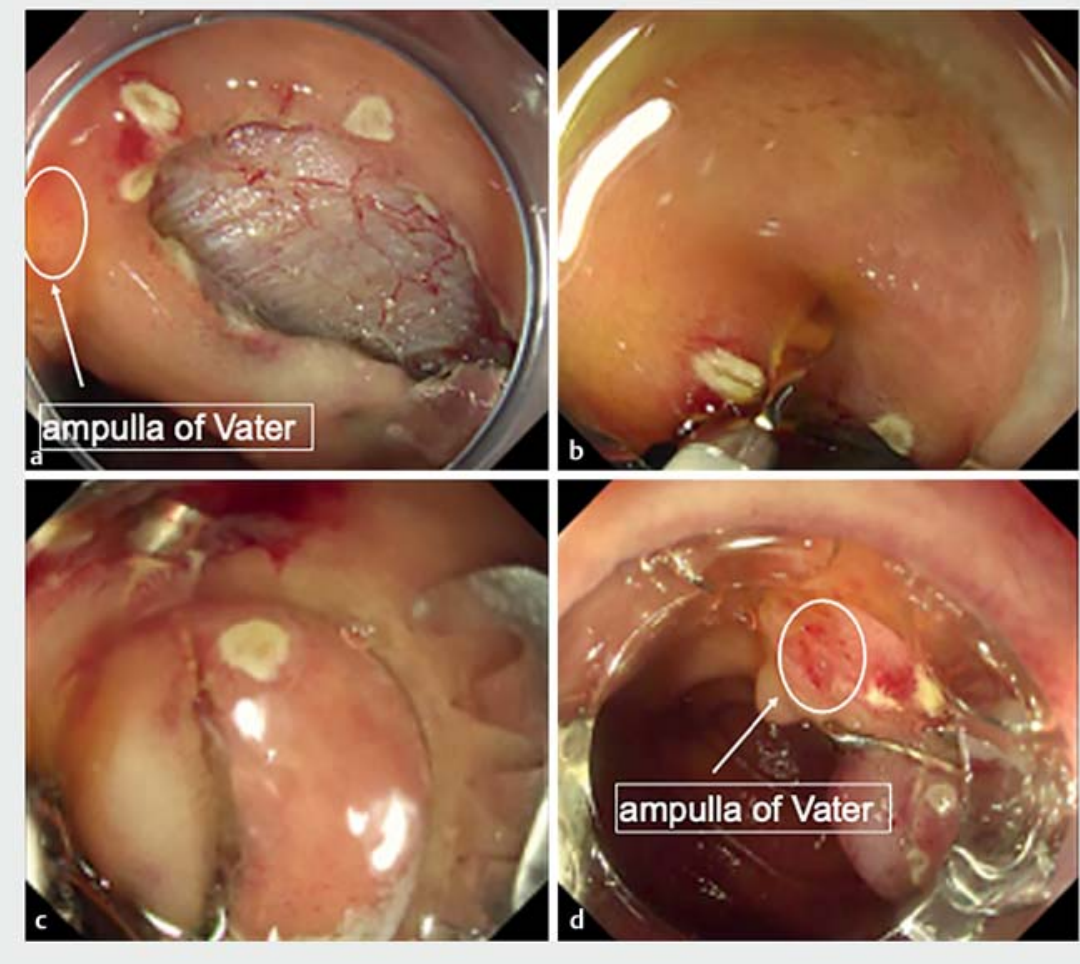

- Fig. 1 Endoscopic images showing: a the ulcer floor after endoscopic submucosal dissection of a lesion adjacent to the ampulla of Vater; $\mathbf{b}$ an anchor clip placed on the ampulla side of the ulcer floor; $\mathbf{c}$ an over-the-scope (OTS) clip being placed after confirming the anchor clip is outside the hood; $\mathbf{d}$ complete closure of the ulcer floor with the OTS clip, with accidental closure of the ampulla of Vater having been avoided.

Endoscopy_UCTN_Code_TTT_1AO_2AB

Competing interests

The authors declare that they have no conflict of interest.

The authors

Takashi Muramoto ${ }^{1}$, Ken Ohata ${ }^{1}$, Rindo Ishii ${ }^{1}$, Ryoju Negishi ${ }^{1}$, Yohei Minato ${ }^{1}$, Nobuyuki Matsuhashi

1 Department of Gastrointestinal Endoscopy, NTT Medical Center Tokyo, Tokyo, Japan

2 Department of Gastroenterology, NTT Medical Center Tokyo, Tokyo, Japan
Corresponding author

Ken Ohata, MD, PhD

Department of Gastrointestinal Endoscopy, NTT Medical Center Tokyo, 5-9-22 HigashiGotanda, Shinagawa-Ku, Tokyo, 141-8625, Japan

ken.ohata1974@gmail.com

\section{References}

[1] Tashima T, Ohata K, Sakai E et al. Efficacy of an over-the-scope clip for preventing adverse events after duodenal endoscopic submucosal dissection: a prospective interventional study. Endoscopy 2018; 50: 487496 


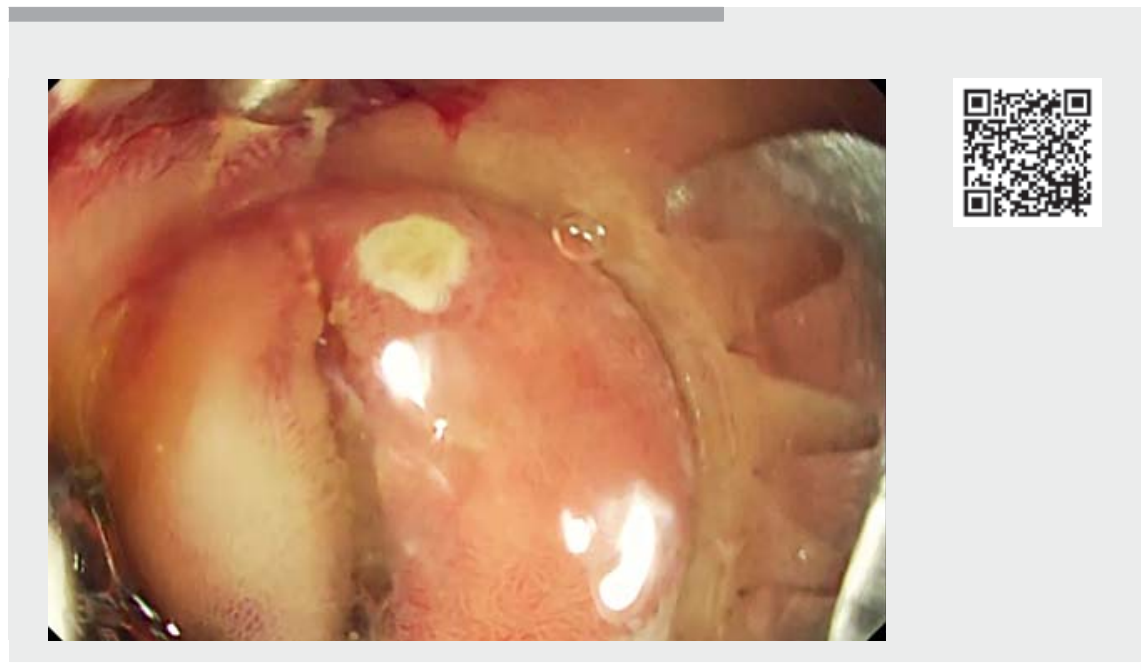

$\checkmark$ Video 1 A technique for safe ulcer floor closure using an over-the-scope clip after endoscopic submucosal dissection of a lesion adjacent to the ampulla of Vater.

[2] Ohata K, Sakai E, Suzuki Y et al. Risk factors of delayed bleeding after endoscopic resection of superficial non-ampullary duodenal epithelial tumors and prevention by overthe-scope and conventional clipping. Dig Endosc 2021; 33: 390-398

[3] Kato M, Ochiai Y, Fukuhara S et al. Clinical impact of closure of the mucosal defect after duodenal endoscopic submucosal dissection. Gastrointest Endosc 2019; 89: 8793
Bibliography

Endoscopy 2022; 54: E374-E375

DOI 10.1055/a-1541-7381

ISSN 0013-726X

published online 9.8 .2021

(C) 2021. Thieme. All rights reserved.

Georg Thieme Verlag KG, Rüdigerstraße 14 , 70469 Stuttgart, Germany

\section{ENDOSCOPY E-VIDEOS}

https://eref.thieme.de/e-videos

回回 Endoscopy E-Videos is an gen access online section, 回: reporting on interesting cases and new techniques in gastroenterological endoscopy. All papers include a high quality video and all contributions are freely accessible online. Processing charges apply (currently EUR 375), discounts and wavers acc. to HINARI are available. pancreatitis due to clipping of the ampu with over-the-scope clip as a complication of bleeding duodenal ulcer treatment. Cureus 2020; 12: e8963

[5] Fukuhara S, Kato M, Iwasaki E et al. External drainage of bile and pancreatic juice after endoscopic submucosal dissection for duodenal neoplasm: Feasibility study (with video). Dig Endosc 2020. doi:10.1111/ den.13907 